\title{
Relationship between sources and manifestations of stress among faculty members in Isabela State University
}

\author{
Helena B. Florendo ${ }^{1}$, Annaliza R. Hernando ${ }^{2}$ \\ ${ }^{1}$ College of Arts and Sciences, Isabela State University, Echague, Isabela, Philippines \\ ${ }^{2}$ Aurora Senior High School, Aurora, Isabela, Philippines
}

\begin{abstract}
Article Info
Article history:

Received Jan 15, 2021

Revised May 8, 2021

Accepted Jun 15, 2021

\section{Keywords:}

Faculty

Higher education

Level of stress

Philippines

Teachers

ABSTRACT

Stress is inevitable in any workplace. Stressed teachers in every school are prone to exhaustion and commit errors. In the Philippines, few studies have been discussed due to stress among faculty members, especially in tertiary education. In this study, the researchers shed light on sources, manifestations, and levels of stress, and discovered the relationship between sources and their manifestations among faculty members of the eight colleges of the Isabela State University-Main Campus. Data were randomly collected from 165 respondents, through the Teacher Stress Inventory developed by Fimian. Data revealed that the main sources and manifestations of stress by the respondents were Work-related and Professional Investment, and Fatigue Manifestations. The level of stress among the respondents was moderate. Likewise, the sources and manifestations of stress were found significantly correlated to each other. Results of the study press on the development of a proposed Stress Management Program supportive and essential in managing and coping stress of the faculty members.
\end{abstract}

This is an open access article under the CC BY-SA license.

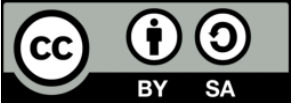

\section{Corresponding Author:}

Helena B. Florendo

College of Arts and Sciences

Isabela State University

San Fabian, Echague, Isabela 3309, Philippines

Email: helena.florendo28@gmail.com

\section{INTRODUCTION}

Stress seems prevalent among all teachers working at different levels of educational institutions. Since the teaching profession is described as having a high-stress level [1]-[4], sources were derived from time, social relationships, administrative work, student discipline problems, lack of motivation, and value conflicts [5], [6]. Also, teachers' work stress is taken from ill behaviors and growing population of students, work during weekends and even at night, multi-tasking roles, and deteriorating resources [7], [8]. Other probable sources of stress include the course of advancement, globalization, and transfer/privatization [9], the lack or absence of administrative support [10], school culture, working situation, misconduct of students, and Type a personality [11]. When faculty members are stressed, they do not function effectively, especially when the level of stress is exceeding what is normal. When it is excessive, it is detrimental to individual efficiency and effectiveness, and health condition. Psychological burnout [12], unfavorable student-teacher relationship, and school environment can cause stress to faculty members [13]. From the perspective of positive psychology, determining stressors in the workplace and developing a program on how to address this problem is of great value [5].

Around the globe, there were researches on stress from both developed and developing counties but limited studies were conducted among faculty on higher education. This study is timely since there is a recent 
call for Filipino researchers to conduct stress-related research among faculty in the Philippines in public higher education. The dearth of studies on stress among faculty in higher education in the Philippines prompted the researcher to embark on this research. The result of this study will greatly contribute to Philippine literature.

The main concern of this research was to determine the relationship between the sources and manifestations of stress experienced by the faculty members of Isabela State University-Main Campus. Specifically, this research attempted to answer the following objectives: 1) determine the sources of stress encountered by the faculty members of Isabela State University-Main Campus; 2) identify the manifestations of stress experienced by the respondents; 3 ) determine the level of stress experienced by the respondents; and 4) discover the relationship between the sources and manifestations of stress experienced by the faculty members of Isabela State University-Main Campus.

\section{RESEARCH METHOD}

This study utilized the descriptive-correlational method of research. Frequency counts and mean scores were used to analyze data, and Pearson $\mathrm{r}$ was employed to test the hypothesis posed in this study. The study was conducted at the Isabela State University-Main Campus. A total of 165 faculty members participated in this study which were randomly selected by the researchers who gave their consent to participate. These are compositions of permanent and contractual faculty of the eight colleges on the main campus of the University. The main tool used in this study was the teacher stress inventory (TSI) [14], a 49item questionnaire with ten (10) factors that assesses the level of stress experienced by the faculty member. The validity and reliability of the instrument had already been proven [14].

The survey-questionnaire was divided into two parts. The first part was designed to gather personal information of the respondents such as name (optional) and place of work (college). The second part is the teachers stress inventory. In the inventory, the sources and manifestations of stress were categorized. The five sources of stress are as follows: time management (8 items), work-related stressors (6 items), professional distress (5 items), discipline and motivation (6 items), and professional investment (4 items). The five manifestations of stress are the following: emotional manifestations ( 5 items), fatigue manifestations (5 items), cardiovascular manifestations (3 items), gastronomic manifestations (3 items), and behavioral manifestations (4 items). The TSI was used to identify the sources and manifestations of stress and to assess the strength of stress levels of the faculty members of Isabela State University-Main Campus.

The Teacher Stress Inventory used a 5-point Likert Scale with weights and qualitative interpretation, 5 is the highest with a qualitative interpretation of always and 1 is the lowest with a qualitative interpretation of never. For the Total Strength Scale and Interpretation of Teacher Stress Inventory, levels of stress and strength scale, the highest is significantly strong with a score of 3.48, and an above, moderate level of stress is 1.49-3.47, while the lowest stress level is weak with 1.48 below the strength scale.

A letter of request for the conduct of the study in the different colleges of Isabela State UniversityMain Campus was prepared and approved by the management. Faculty members as primary respondents were oriented about the purpose of the study. They were given informed consent; likewise, the confidentiality of their responses shall not be disclosed. The inventory was administered during the vacant time of faculty members, then the retrieval process followed.

\section{RESULTS AND DISCUSSION}

\subsection{Sources of the stress of the respondents}

Table 1 presents the mean scores and descriptions of the sources of stress of the respondents. WorkRelated Stress "too much work to do" obtained the highest mean score of 4.53 with a description of "always". Professional Distress indicated that "lack of promotion and advancement opportunities" got a high mean score of 3.59 with a descriptive interpretation of "often". Under Professional Investment, the "lack of opportunities for improvement" garnered the highest mean score of 4.08 with a descriptive interpretation of "often". For Discipline and Motivation, "teaching students who are poorly motivated" got the highest mean score of 4.10. For Time Management, "Do more than one thing at a time" was rated "often" with a mean score of 3.37 .

Based on the findings, it proved that stress can cause mental, behavioral, and even biological burdens to a person. The sources of stress identified are those with little salary, too much work, difficult control of situations, lack of support, the restricted possibility of development, and ambiguous work opportunities [11]. Inadequate office facilities, lack of books, computers, internet facilities, too much paper works, overcrowding in the classroom, professional development is inadequate, unavailability of medical facilities, lack of time to relax, and poor academic background are major contributory factors to teacher's 
stress [15]. The attitudes of teachers regarding students could also be linked to their burnout experiences [16]. If there is very high stress or burnout in the workplace, the quality of interaction between teacher-student is affected; lesser emotional support and poorer classroom structure [17]. Stressed teachers due to the overpowering mandates of their work can not manage their classroom very well; interactions with the students are poor and they can not respond well according to students' needs and concerns [18]. There are student's behavioral problems if there is a great number of learners in the classroom [18]. Workload and time strain, misbehavior or misconduct of students, lack of harmony concerning personal beliefs, and the values in the school are also reasons for stress [19]. Teachers who have high emotional well-being contribute to the healthier management of the classroom. As a result, a conducive classroom atmosphere will be established, the quality of teacher-student interactions and productivity of teachers are expected [20].

Table 1. Mean and interpretation of the five categories of the sources of stress

\begin{tabular}{lcc}
\hline \multicolumn{1}{c}{ Sources of stress } & Mean score & Descriptive interpretation \\
\hline Work-related stress & & \\
Too much work to do & 4.53 & Always \\
Too much administrative paperwork & 4.44 & Often \\
School day pace is too fast & 4.28 & Often \\
Caseload/ class is too big & 4.11 & Often \\
Little time to prepare (e.g. Lesson plans) & 4.01 & Often \\
Personal priorities being shortchanged & 3.65 & Often \\
Professional distress & & \\
Lack promotion or advancement opportunities & 3.59 & Often \\
Lack recognition & 3.51 & Often \\
Not progressing rapidly in job & 3.31 & Sometimes \\
Receive an inadequate salary & 3.01 & Sometimes \\
Need more status and respect & 2.72 & Sometimes \\
Professional investment & & \\
Lack opportunities for improvement & 4.08 & Often \\
Personal opinions not sufficiently aired & 3.99 & Often \\
Not emotionally/intellectually stimulated & 3.10 & Sometimes \\
Lack control over decisions & 2.54 & Sometimes \\
Discipline and Motivation & & \\
Teaching students who are poorly motivated & 4.1 & Often \\
Students who would do better if they tried harder & 3.59 & Often \\
Having to monitor students' behavior & 3.27 & Sometimes \\
Discipline problems in my classroom & 3.16 & Sometimes \\
Inadequate or poorly defined discipline policies & 3.04 & Sometimes \\
Authority rejected by students/administrators & 2.55 & Sometimes \\
Time management & & \\
Do more than one thing at a time & 3.37 & Often \\
Not enough time to get things done & 3.22 & Sometimes \\
Have little time to relax & 3.13 & Sometimes \\
Feel uncomfortable wasting time & 2.99 & Sometimes \\
Become impatient & 2.86 & Sometimes \\
Think about unrelated matters & 2.86 & Sometimes \\
Rush in my speech & 2.66 & Sometimes \\
\hline Means and Interpretation are based on the following scale: $1.00-1.45$ Never; & $1.46-.2 .45$ Seldom; $2.46-3.45$ Sometimes; \\
3.46-4.45 Often; 4.46-5.00 Always & & \\
& &
\end{tabular}

Among different universities, there is competition, the evaluation/accreditation/audit by different agencies or regulatory boards, and anticipated distribution or delivery of exceptional service to the stakeholders may influence the functioning of faculty members [21]. The absence of motivation to work, facilities, and poor relationships are causes of stress in the workplace [21]. Advancement in career and recognition is also crucial in higher education [21]. Faculty are required to take advanced studies for professional development. If the faculty is working and studying at the same time, lots of pressure are encountered. They are burdened financially if no scholarship is availed, and limitations in time are problems that cause stress.

\subsection{Manifestations of the stress of respondents}

As shown in Table 2, all items under emotional manifestations were rated as "barely noticeable". "Feeling vulnerable" recorded the highest mean score of 2.23. Behavioral Manifestations were also found to be "barely noticeable". "Calling in sick" and "using over-the-counter-drugs" both got the highest mean score of 2.26. Under cardiovascular manifestations, all items were "barely noticeable". "Feelings of heart-pounding or racing" got the highest mean score of 2.23. Based on gastronomic manifestations, "stomach cramps" obtained the highest mean score of 3.12. Among the different manifestations of stress, Fatigue obtained the 
highest mean score with an interpretation of "very noticeable". Under this category, "physical exhaustion" was found to be "extremely noticeable" with a mean score of 4.95 .

Table 2. Mean and interpretation of the five categories of the manifestations of stress

\begin{tabular}{lcc}
\hline \multicolumn{1}{c}{ Manifestations of stress } & Mean scores & Descriptive interpretation \\
\hline Emotional manifestations & & \\
Feeling vulnerable & 2.23 & Barely noticeable \\
Feeling unable to cope & 2.20 & Barely noticeable \\
Feeling anxious & 2.17 & Barely noticeable \\
Feeling depressed & 2.13 & Barely noticeable \\
Feeling insecure & 2.11 & Barely noticeable \\
Behavioral manifestations & & \\
$\quad$ Calling in sick & 2.26 & Barely noticeable \\
Using over-the-counter drugs & 2.26 & Barely noticeable \\
Using prescription drugs & 2.06 & Barely noticeable \\
$\quad$ Using alcohol & 1.78 & Barely noticeable \\
Cardiovascular manifestations & & \\
Feelings of heart-pounding or racing & 2.23 & Barely noticeable \\
Feelings of increased blood pressure & 2.13 & Barely noticeable \\
Rapid/shallow breath & 1.97 & Barely noticeable \\
Gastronomic manifestations & & \\
$\quad$ Stomach cramps & 3.12 & Moderately noticeable \\
$\quad$ Stomach acid & 2.68 & Moderately noticeable \\
Stomach pain of extended duration & 2.20 & Barely noticeable \\
Fatigue manifestations & & \\
$\quad$ Physical exhaustion & 4.95 & Extremely noticeable \\
$\quad$ Physical weakness & 4.74 & Extremely noticeable \\
$\quad$ Becoming fatigued in short time & 4.51 & Very noticeable \\
Sleeping more than usual & 3.55 & Very noticeable \\
Procrastinating & 3.40 & Moderately noticeable \\
\hline
\end{tabular}

Scores and Interpretation: 1.00-1.45=not noticeable; $1.46-2.45=$ barely noticeable; $2.46-3.45=$ moderately noticeable; $3.46-4.45=$ very noticeable $4.46-5.00=$ extremely noticeable

The psychological and physiological functioning of a person will be affected due to stress. If there is stress, undesirable emotions are expressed. There were anxious faculty and others felt insecure due to job stress. Migraine and other health concerns like back pain are encountered by faculty who are distressed. The stressed teachers may have symptoms of depression that might lead to a minimal organization in the classroom, have ineffective behavioral supervision, and the emotional support to students becomes less [21]. Among teachers who are stressed, anxiety and depression were noted [22]. Stress can also lead to more consumption of alcohol, nicotine, drugs, as well as sleeping and digestive problems [23].

\subsection{Level of the stress of the respondents}

Table 3 presents the mean scores and descriptive interpretations of the total strength score of the teacher stress inventory on the categories of the sources and manifestations of stress. The mean and interpretation of the total strength score of the TSI reveal the level of stress among the respondents. Table 3 shows that the total mean score is 2.96 indicating that the total stress level of the faculty is "moderate".

Table 3. Mean and interpretation of the total strength score of teacher stress inventory

\begin{tabular}{lcc}
\hline Sources and manifestations stress & Mean score & Descriptive interpretation \\
\hline Work-related stress & 4.17 & Significantly strong \\
Professional distress & 3.22 & Moderate \\
Professional investment & 4.10 & Significantly strong \\
Discipline and motivation & 2.74 & Moderate \\
Time management & 3.02 & Moderate \\
Emotional manifestations & 2.03 & Moderate \\
Behavioral manifestations & 1.92 & Moderate \\
Cardiovascular manifestations & 1.92 & Moderate \\
Gastronomic manifestations & 2.45 & Moderate \\
Fatigue manifestations & 4.00 & Significantly strong \\
$\quad$ Total mean & 2.96 & Moderate \\
Score and Interpretation: 1.48 below- Significantly weak; 1.47-3.47 Moderate; 3.48 above- Significantly \\
strong
\end{tabular}

Int. J. Public Health Sci., Vol. 10, No. 3, September 2021 : 465 - 471 
The finding of this research is contrary to the description that teaching has a high level of stress [1][4], [24]. Some factors possibly affect the level of stress among teachers. Though faculty members in elementary, secondary, and tertiary education may be exposed to the same or similar causes of stress, they might differ in the frequency and intensity of stressful experiences since how they deal with their stress will greatly affect their stress level. The finding also indicates that among the five (5) sources of stress, workrelated stress and professional investment with mean scores of 4.17 and 4.10 with the description "significantly strong" seems to intensely disturb the respondents. Among the five (5) manifestations of stress, fatigue manifestations got the highest mean score of 4.0 which is interpreted as "significantly strong" which appears to greatly affect the faculty in Isabela State University-Main campus.

\subsection{Relationship between sources and manifestations of the stress of respondents}

Table 4 presents the correlation between the Sources and Manifestations of Stress. The computed value $(\mathrm{r}$-value $=0.401, \mathrm{p}$-value $=0.000)$ shows that there is a significant relationship between Professional Distress and the Emotional Manifestations of stress. Behavioral manifestation of stress has a significant relationship to the Professional Distress ( $\mathrm{r}$-value $=0.317, \mathrm{p}$-value $=0.000$ ). Cardiovascular manifestation of stress was found to have a significant relationship with Professional Distress ( $r$-value $=0.302, p$-value $=0.000$ ). There is a significant relationship between the Professional Distress and the Gastronomic Manifestation of stress $(\mathrm{r}$-value $=0.153$, $\mathrm{p}$-value $=0.049$ ).

Table 4. Relationship between sources and manifestations of stress

\begin{tabular}{|c|c|c|c|c|c|c|c|c|c|c|}
\hline \multirow{3}{*}{$\begin{array}{c}\text { Categories of the sources } \\
\text { of stress }\end{array}$} & \multicolumn{10}{|c|}{ Categories of the manifestations of stress } \\
\hline & \multicolumn{2}{|c|}{ Emotional } & \multicolumn{2}{|c|}{ Behavioral } & \multicolumn{2}{|c|}{ Cardiovascular } & \multicolumn{2}{|c|}{ Gastronomic } & \multicolumn{2}{|c|}{ Fatigue } \\
\hline & $\begin{array}{c}\text { Pearson } \\
\mathrm{r}\end{array}$ & $\begin{array}{c}\mathrm{p}- \\
\text { value }\end{array}$ & $\begin{array}{c}\text { Pearson } \\
\mathrm{r} \\
\end{array}$ & $\begin{array}{c}\mathrm{p}- \\
\text { value }\end{array}$ & $\begin{array}{c}\text { Pearson } \\
\mathrm{r} \\
\end{array}$ & $\begin{array}{c}\mathrm{p} \\
\text { value }\end{array}$ & $\begin{array}{c}\text { Pearson } \\
\mathrm{r}\end{array}$ & $\begin{array}{c}\mathrm{p}- \\
\text { value }\end{array}$ & $\begin{array}{c}\text { Pearson } \\
\mathrm{r}\end{array}$ & $\begin{array}{c}\mathrm{p}- \\
\text { value }\end{array}$ \\
\hline Work-related stress & $-0.002^{\mathrm{ns}}$ & 0.984 & $0.192 *$ & 0.013 & $0.052 *$ & 0.508 & $0.167 *$ & 0.032 & $0.043^{\mathrm{ns}}$ & 0.481 \\
\hline Professional distress & $0.401 *$ & 0.000 & $0.317 *$ & 0.000 & $0.302 *$ & 0.000 & $0.153 *$ & 0.049 & $0.115^{\mathrm{ns}}$ & 0.14 \\
\hline Professional investment & $0.150 *$ & 0.054 & $0.254 *$ & 0.001 & $0.189 *$ & 0.015 & $0.256^{*}$ & 0.001 & $0.136^{*}$ & 0.081 \\
\hline $\begin{array}{l}\text { Discipline and } \\
\text { motivation }\end{array}$ & $0.150 *$ & 0.054 & $0.126^{\mathrm{ns}}$ & 0.108 & $0.210 *$ & 0.007 & $0.185^{*}$ & 0.017 & $0.002^{\mathrm{ns}}$ & 0.981 \\
\hline Time management & $0.480 *$ & 0.000 & $0.392 *$ & 0.000 & $0.356 *$ & 0.000 & $0.308^{*}$ & 0.000 & $0.251^{*}$ & 0.001 \\
\hline
\end{tabular}

Legend: * significant

Professional Investment was found to be significantly related with the Emotional Manifestations of stress $(\mathrm{r}$-value $=0.150, \mathrm{p}$-value $=0.054)$. The computed value $(\mathrm{r}$-value $=0.254, \mathrm{p}$-value $=0.001)$ reveals that there is significant relationship between Professional Investment and Behavioral Manifestation of stress. The Cardiovascular Manifestation of stress was found to have a significant relationship with the Professional Investment ( $\mathrm{r}$-value $=0.189$, $\mathrm{p}$-value $=0.015$ ). Gastronomic as a manifestation of stress has a significant relationship with Professional Investment ( $\mathrm{r}$-value $=0.256$, $\mathrm{p}$-value $=0.001)$. The computed value ( $\mathrm{r}$ value $=0.136$, $p$-value $=0.081$ ) shows that there is a significant relationship between Professional Investment and Fatigue as a manifestation of stress.

Discipline and Motivation were found to have a significant relationship with the Emotional Manifestation of stress ( $\mathrm{r}$-value $=0.150, \mathrm{p}$-value $=0.054)$. The computed value $(\mathrm{r}$-value $=0.210, \mathrm{p}$-value $=0.007)$ shows that there is a significant relationship between Discipline and Motivation and Cardiovascular as a manifestation of stress. Gastronomic was also found to have a significant relationship with Discipline and Motivation $(\mathrm{r}$-value $=0.185$, $\mathrm{p}$-value $=0.017$ ).

Time Management is significantly related to the Emotional Manifestation of stress ( $r$-value $=0.480$, $\mathrm{p}$-value $=0.000$ ). The Behavioral Manifestation of stress on the other hand, has significant relationship to Time Management ( $\mathrm{r}$-value $=0.392$, $\mathrm{p}$-value $=0.000$ ). Cardiovascular as a manifestation of stress was found to have a significant relationship with Time Management ( $\mathrm{r}$-value $=0.356, \mathrm{p}$-value $=0.000$ ). The computed value $(\mathrm{r}$-value $=0.308, \mathrm{p}$-value $=0.000)$ reveals that there is a significant correlation between Time Management and Gastronomic as a manifestation of stress. Fatigue a was also found to have significant relationship with Time Management ( $r$-value $=0.251$, $p$-value $=0.001$ ).

The result of this study is in agreement with the findings of several studies. Based on research, those who are experiencing stress likely show signs and symptoms of psychological distress like headaches, high blood pressure, and stomach ache [25]. There are physical consequences like palpitation, increase in respiration, asthma attacks, and digestion problems due to stress [26]. Teaching is stressful and lots of faculty members experience various levels of tension which may result in inferior teaching, unhealthy relationship, and low self-esteem [26]. Pressures from work may also result in stress and when exposed to a long period of time may lead to ailments such as depression, backaches, inability to sleep, and migraine [27]. 
It was also found out that time pressure encountered by teachers is a critical source of stress since it predicts burnout and emotional exhaustion [19], [28]. Students' behavior which is difficult to manage and students' motivation to learn are predictive of teachers' stress [29]. Increase workload of faculty members from a great number of paper works, curriculum revision, handling projects related to research or academics, meetings, and inequality of salary or reward/incentive from a voluminous workload are all related to stress [2]. Stress in the workplace may lead to reduced productivity [30]. If the faculty stress would not be managed, this might be detrimental to the institution since it affects performance in the workplace. It is a challenge to ensure high-quality education when faculty in higher education can not cope with educational stress [31].

Faculty in higher education are found to be affected by their work environment that influences their stress level, thus, a more caring and compassionate environment and a better means of humane relationship may be implemented [32].

\section{CONCLUSION}

Findings of the study revealed that Work-Related stress and Professional Investment are the major sources of stress while Fatigued manifestations are the main indicators of stress among the faculty in Isabela State University main campus. Administrators and co-workers may provide frequent and better interactions among faculty and enough training or preparations may be considered in the performance of their job. An orientation program may also be conducted for the new faculty to provide better groundwork in their job. Adequate facilities and improved physical plants may be provided to improve the working environment of the faculty. Planning of activities may be done before the semester starts. The plans have to be implemented and regularly monitored to avoid cramming in the implementation of activities that may cause stress. Faculty experienced fatigue when they got stress, hence, they were physically exhausted and became weak. It is then recommended that a stress management program may be considered for implementation to help faculty members reduce their level of stress. Awareness of the symptoms and sources of stress can possibly help faculty members to manage and cope with their stress. A qualitative or mixed method of research on faculty stress in higher education is also encouraged for a clearer picture of the stress encountered by the faculty.

\section{REFERENCES}

[1] Herman K. C., Hickmon-Rosa J. E., and Reinke W. M., "Empirically derived profiles of teacher stress, burnout, self-efficacy, and coping and associated student outcomes," Journal of Positive Behavior Interventions, vol. 20 , no. 2, pp. 90-100, April 2018.

[2] Shen H. J, Basri R., and Asimiran S, "Relationship between job stress and job satisfaction among teachers in a private and international school in Malaysia," International Journal of Academic Research in Business and Social Sciences, vol. 8, no. 12, pp. 275-286, Dec. 2018.

[3] Othman Z. and Sivasubramaniam V, "Depression, anxiety, and stress among secondary school teachers in Klang, Malaysia, Int Med J, vol. 26, no. 2, pp. 71-74, April 2019.

[4] Rodrigues L. T., Lago E. C., Almeida C. A, Ribeiro I. P, and Mesquita G. V, "Stress and depression in teachers from a public education institution," Enfermería Global, vol. 19, no. 1, pp. 232-242, 2020.

[5] Du Plessis M., "Model of coping with occupational stress of academics in a South African higher education institution," SA Journal of Industrial Psychology, vol. 46, no. 1, pp. 1-1, 2020.

[6] Skaalvik E. M and Skaalvik S., "Teacher stress and teacher self-efficacy as predictors of engagement, emotional exhaustion, and motivation to leave the teaching profession," Creative Education, vol. 7, no. 13, p. 1785, 2016.

[7] Kelly C, "Stress in the higher education sector: Causes and yoga-mindfulness interventions," Journal of Yoga and Physiotherapy, vol. 3, no. 3, pp.1-4, Nov. 2017.

[8] Sharma S. and Shakir M., "Stress management among teachers: The Bhagavad Gita's approach," Educational Quest-An International Journal of Education and Applied Social Sciences, vol. 8, no. 3, pp. 649-58, 2017.

[9] Shrivastava A. and Shukla N., "A critical review on occupational stress factors affecting faculty members working in higher educational institutions in India," Pacific Business Review International, vol. 10 no. 3, pp. 129-38, Sept. 2017.

[10] Haydon T., Leko. M. M., and Stevens D., "Teacher stress: Sources, effects, and protective factors," Journal of Special Education Leadership, vol. 1, no. 31, pp. 99-107, Sept 2018.

[11] Obryan. S, "Work-related stress and coping strategies for elementary teachers," 2019. [Online]. Available: https://repository.stcloudstate.edu/cgi/viewcontent.cgi?article=1072\&context=edad_etds

[12] Fitchett P. G, McCarthy C. J., Lambert R. G., and Boyle L., “An examination of US first-year teachers' risk for occupational stress: Associations with professional preparation and occupational health," Teachers and Teaching, vol. 24, no. 2, pp. 99-118, Feb. 2018.

[13] Harmsen R., Helms-Lorenz M., Maulana R., Van Veen K., and Van Veldhoven M., "Measuring general and specific stress causes and stress responses among beginning secondary school teachers in the Netherlands," International Journal of Research and Method in Education, vol. 42, no. 1, pp. 91-108, Jan. 2019. 
[14] Tan J. S., "Factors affecting stress among faculty members of public universities in the Philippines: A multiple regression analysis," International Journal of Psychological Studies, vol. 9, no. 3, pp.56-69, Aug. 2017.

[15] Tahseen N., "Work-related stress among teacher-educators: Evidence from Punjab," Pakistan Journal of Psychological Research, vol. 3, no. 2, pp. 357-75, Dec. 2015.

[16] Saloviita T. and Pakarinen E., "Teacher burnout explained: Teacher-, student-, and organisation-level variables," Teaching and Teacher Education, vol. 97, p. 103221, Jan. 2021.

[17] Lasebikan V. O., "Expert panel's modification and concurrent validity of the Teacher Stress Inventory among selected secondary school teachers in Nigeria," Psicologia: Reflexão e Crítica, vol. 29, pp. 1-7, 2016.

[18] Braun S. S., Roeser R. W., Mashburn A. J., and Skinner E., "Middle school teachers' mindfulness, occupational health and well-being, and the quality of teacher-student interactions," Mindfulness, vol. 10, no. 2, pp. 245-55, Feb. 2019.

[19] Skaalvik E.M., and Skaalvik S., "Job Satisfaction, stress and coping strategies in the teaching profession-What do teachers say?" International Education Studies, vol. 8, no. 3, pp. 181-92, 2015.

[20] Oberle E., and Schonert-Reichl K.A., "Stress contagion in the classroom? The link between classroom teacher burnout and morning cortisol in elementary school students," Social Science and Medicine, vol. 159, pp. 30-7, June 2016.

[21] Mwenda F. K, Kiflemariam A., and Kimani S. W., "An assessment of the relationship between job stressors and faculty performance in selected private universities in Kenya," International Journal of Education and Research, vol. 7, no.7, pp. 45-56, 2019.

[22] Desouky D. and Allam H., "Occupational stress, anxiety and depression among Egyptian teachers," Journal of Epidemiology and Global Health, vol. 7, no. 3, pp.191-198, Sept. 2017.

[23] Tran C. T., Tran H. T., Nguyen H. T., Mach D. N., Phan H. S., and Mujtaba B.G., "Stress management in the modern workplace and the role of human resource professionals," Business Ethics and Leadership, vol. 4, no. 2, pp. 26-40, 2020.

[24] Othman Z. and Sivasubramaniam V., "Depression, anxiety, and stress among secondary school teachers in Klang, Malaysia", International Medical Journal, vol. 26, no. 2, pp.71-74, 2019.

[25] Mohamed T., "Sources of occupational stress among teachers: A field of study for teachers working in Libyan Schools in Turkey," International Journal of Academic Research in Economics and Management Sciences, vol. 7, no. 1, pp. 1-5, 2018.

[26] Manabete S. S., John C. A., Makinde A. A., and Duwa S. T., "Job stress among school administrators and teachers in Nigerian secondary schools and technical colleges," International Journal of Education, Learning and Development, vol. 4, no. 2, pp. 1-9, 2016.

[27] Kaswan S. S, Ramdeva, R. A., and Sandeep, Ku. "Mental stress in corporate sector and its yogic management." Tantia University Journal of Homoeopathy and Medical Science, vol. 3, no. 4, Oct.-Dec. 2020.

[28] Aparisi D., Torregrosa. M. S., Inglés. C. J., and García Fernández J. M., "Stress, burnout and health in a sample of Spanish teachers," Advances in Higher Educucation, vol. 3, no. 1, pp. 1-10, 2019.

[29] Asa F. T. and Lasebikan. V. O., "Mental health of teachers: Teachers' stress, anxiety, and depression among secondary schools in Nigeria," International Neuropsychiatric Disease Journal, vol. 7, no. 4, pp. 1-10, July 2016.

[30] Nie Y. and Sun H., "Why do workaholics experience depression? A study with Chinese University teachers," Journal of Health Psychology, vol. 21, no. 10, pp. 2339-2346, Oct. 2016

[31] Liu M. and Yan Y., "Anxiety and stress in in-service Chinese University Teachers of Arts," International Journal of Higher Education, vol. 9, no. 1, pp. 237-248, 2020.

[32] Adom D., Chukwuere J., and Osei M., "Academic stress among faculty and students in higher institutions," Pertanika Journal of Social Sciences and Humanities, vol. 28, no. 2, pp. 1055-1064, June 2020. 